\title{
Highly variable taxa-specific coral bleaching responses to thermal stresses
}

\author{
Timothy R. McClanahan ${ }^{1, *}$, Emily S. Darling ${ }^{1,2}$, Joseph M. Maina ${ }^{3}$,
} Nyawira A. Muthiga ${ }^{1}$, Stephanie D'agata ${ }^{1,3}$, Julien Leblond ${ }^{1}$, Rohan Arthur ${ }^{4,5}$, Stacy D. Jupiter ${ }^{1,6}$, Shaun K. Wilson ${ }^{7,8}$, Sangeeta Mangubhai ${ }^{1,6}$, Ali M. Ussi ${ }^{9}$, Mireille M. M. Guillaume ${ }^{10,11}$, Austin T. Humphries ${ }^{12,13}$, Vardhan Patankar $^{14,15}$, George Shedrawi ${ }^{16,17}$, Julius Pagu ${ }^{18}$, Gabriel Grimsditch ${ }^{19}$

\author{
${ }^{1}$ Wildlife Conservation Society, Marine Program, Bronx, NY 10460, USA \\ ${ }^{2}$ Department of Ecology and Evolutionary Biology, University of Toronto, Toronto, ON M5S 3B2, Canada \\ ${ }^{3}$ Faculty of Science and Engineering, Department of Earth and Environmental Science, Macquarie University, Sydney, \\ NSW 2109, Australia \\ ${ }^{4}$ Nature Conservation Foundation, Amritha 1311, $12^{\text {th }}$ Main, Vijaynagar $1^{\text {st }}$ Stage Mysore 570017, India \\ ${ }^{5}$ Center for Advanced Studies (CEAB), C. d'Acces Cala Sant Francesc, 14, 17300 Blanes, Spain \\ ${ }^{6}$ Wildlife Conservation Society, Melanesia Program, 11 Ma'afu Street, Suva, Fiji \\ ${ }^{7}$ Marine Science Program, Department of Biodiversity, Conservation and Attractions, Kensington, WA 6101, Australia \\ ${ }^{8}$ Oceans Institute, University of Western Australia, Crawley, WA 6009, Australia \\ ${ }^{9}$ Department of Natural Sciences, The State University of Zanzibar, Zanzibar, Tanzania \\ ${ }^{10}$ Muséum National d'Histoire Naturelle, Aviv, Laboratoire BOREA MNHN-SU-UCN-UA-CNRS-IRD EcoFunc, 75005 Paris, France \\ ${ }^{11}$ Laboratoire d'Excellence CORAIL, 66860 Perpignan, France \\ ${ }^{12}$ Department of Fisheries, Animal and Veterinary Science, University of Rhode Island, Kingston, RI 02881, USA \\ ${ }^{13}$ Graduate School of Oceanography, University of Rhode Island, Narragansett, RI 02882, USA \\ ${ }^{14}$ Wildlife Conservation Society, 551, 7th Main Road, Rajiv Gandhi Nagar, 2nd Phase, Kodigehalli, Bengaluru - 560097, \\ Karnataka, India \\ ${ }^{15}$ Tata Institute of Fundamental Research, National Centre for Biological Sciences, GKVK Campus, Bangalore 560065 , India \\ ${ }^{16}$ School of Molecular and Life Sciences, Bentley Campus, Curtin University, Perth, WA 6485, Australia \\ ${ }^{17}$ Pacific Community, Division of Fisheries, Aquaculture and Marine Ecosystems, SPC - B.P. D5 - 98848 Noumea, New Caledonia \\ ${ }^{18}$ Mafia Island Marine Park, PO Box 74, Tanzania \\ ${ }^{19}$ IUCN Maldives, Merryrose Building 2nd Floor, Filigas Magu, 20006 Malé, Maldives
}

\begin{abstract}
Complex histories of chronic and acute sea surface temperature (SST) stresses are expected to trigger taxon- and location-specific responses that will ultimately lead to novel coral communities. The 2016 El Niño-Southern Oscillation provided an opportunity to examine largescale and recent environmental histories on emerging patterns in 226 coral communities distributed across 12 countries from East Africa to Fiji. Six main coral communities were identified that largely varied across a gradient of Acropora to massive Porites dominance. Bleaching intensity was taxon-specific and was associated with complex interactions among the 20 environmental variables that we examined. Coral community structure was better aligned with the historical temperature patterns between 1985 and 2015 than the 2016 extreme temperature event. Additionally, bleaching responses observed during 2016 differed from historical reports during past warm years. Consequently, coral communities present in 2016 are likely to have been reorganized by both long-term community change and acclimation mechanisms. For example, less disturbed sites with cooler baseline temperatures, higher mean historical SST background variability, and infrequent extreme warm temperature stresses were associated with Acropora-dominated communities, while more disturbed sites with lower historical SST background variability and frequent acute warm stress were dominated by stress-resistant massive Porites corals. Overall, the combination of taxon-specific responses, community-level reorganization over time, geographic variation, and multiple environmental stressors suggest complex responses and a diversity of future coral communities that can help contextualize management priorities and activities.
\end{abstract}

KEY WORDS: Adaptation - Acclimation - Climate change $\cdot$ Community structure $\cdot$ Geography Stress responses

${ }^{*}$ Corresponding author: tmcclanahan@wcs.org
() The authors 2020. Open Access under Creative Commons by Attribution Licence. Use, distribution and reproduction are unrestricted. Authors and original publication must be credited. 


\section{INTRODUCTION}

The spatial and taxonomic responses of corals to stressful exposure events will determine the future resilience and persistence of coral reefs in the face of rapid climate change (Hughes et al. 2017, 2018a). While climate stress is frequently described as excess heat above mean warm-season background conditions, there are multiple interacting environmental conditions that influence how corals respond to thermal stress, including sea surface temperature (SST) variability, sunlight, water flow, and habitat characteristics (Maina et al. 2008, Grottoli et al. 2014, Ainsworth et al. 2016, Sully et al. 2019). Additionally, coral host acclimation and changes in the microbiome community can further modify responses to environmental exposures (Pandolfi et al. 2011, Palumbi et al. 2014, McClanahan et al. 2019). Therefore, monitoring and evaluating a variety of thermal impacts over gradients of geography, ecologies, and time is critical to identify and guide management interventions to safeguard species and coral reef communities threatened by climate change. Monitoring is also critical for developing predictive models of how coral reefs will respond to emerging thermal stress.

Here, we evaluated how coral taxa and communities responded to a variety of acute thermal exposure metrics in the context of a site's historical SSTs. The study was undertaken on a broad spatial scale to evaluate the geographic context of responses. Further, we evaluated a variety of possible thermal stress metrics to better understand their potential impacts on coral taxa and communities. This study builds on a previous study where bleaching of the whole coral community was examined during the 2016 thermal anomaly and was found to respond most to interacting stressors (McClanahan et al. 2019). We ask here how bleaching responses vary with various thermal anomaly metrics, historical environmental conditions, and specific taxa and communities. Our focus was on the acute responses of 2016 bleaching and associations between long- and short-term SST distribution patterns and coral communities. We hypothesized that coral community composition and responses to thermal stress would be influenced by historical SST patterns, and bleaching responses would be taxa-specific, contextual, and interactive with a variety of potential environmental stresses.

\section{MATERIALS AND METHODS}

We examined the bleaching responses of 30 major coral genera to 20 environmental factors that in- cluded thermal metrics, geography, habitat, depth, coral community, management, and their interactions (Table 1). Further, we evaluated the associations of coral communities with short- (90 d) and longterm (1985-2015) SST patterns at each site.

\subsection{Study sites and field methods}

Between February and September 2016, we conducted 226 bleaching surveys in 12 countries across the Indian and Pacific Oceans using a standard rapid roving observer methodology (McClanahan et al. 2019, Table S1 in the Supplement at www.int-res. com/articles/suppl/m648p135_supp.pdf). For each survey, an observer assessed coral bleaching across a series of haphazard replicate quadrats $\left(\sim 1.5 \mathrm{~m}^{2}\right)$ to assess the frequency and severity of bleaching. Within each quadrat, hard coral colonies $(>5 \mathrm{~cm})$ were identified to genus. Our method required sharing a single taxonomic source for all observers, for which we relied on Veron (2000). However, this widely used taxonomic reference lacks some of the latest and ongoing revisions of the taxonomy of scleractinians as revealed by molecular phylogeny. Yet, Veron's (2000) genera names used in our 2016 surveys cannot be updated because several genera have since been split up, and some species that belonged to the same genus are now assigned to different genera.

Each colony was scored for bleaching severity using 7 categories: $c 0$ : normal; $c 1$ : pale; $c 2: 0-20 \%$ bleached; c3: $21-50 \%$ bleached; $c 4: 51-80 \%$ bleached; $c 5$ : $81-100 \%$ bleached; $c 6$ : recently dead (Fig. 1). Within each quadrat, observers made visual estimates of the average percent cover of live hard coral, live soft coral, and macroalgae (e.g. fleshy or calcareous algae taller than filamentous turf) to the nearest $5 \%$. On each survey, observers conducted an average $( \pm \mathrm{SD})$ of $17.8 \pm 4.7$ quadrats. In some surveys, quadrats were recorded using photographs and colonies were identified and scored for bleaching post hoc by the observer. Observers also recorded depth, habitat type, and management for each survey site.

\subsection{Bleaching metrics and community composition}

For each survey, we calculated 2 standard bleaching metrics: (1) the percentage of bleached coral colonies and (2) bleaching intensity, a weighted average from 7 categories of bleaching severity. For bleaching intensity, we calculated a weighted mean (as per McClanahan et al. 2004, McClanahan et al. 
Table 1. Hypothesized drivers of coral bleaching during the 2016 thermal anomaly. Specific variables were those used for statistical testing in the present study using data from the 226 surveyed sites during the $90 \mathrm{~d}$ window prior to the peak thermal stress and subsequent underwater bleaching surveys

\begin{tabular}{|c|c|c|c|c|c|}
\hline $\begin{array}{l}\text { Hypothesized } \\
\text { driver }\end{array}$ & Model/mechanism & References & $\begin{array}{l}\text { Specific } \\
\text { variable }\end{array}$ & Description & $\begin{array}{l}\text { Variable } \\
\text { range }\end{array}$ \\
\hline Geography & $\begin{array}{l}\text { Historical environmental } \\
\text { conditions will modify responses } \\
\text { to thermal stress }\end{array}$ & $\begin{array}{l}\text { Hughes et al. } \\
(2003,2018 b)\end{array}$ & $\begin{array}{l}\text { Longitude } \\
\text { and } \\
\text { latitude }\end{array}$ & Geographic positions & $140 \times 50^{\circ}$ \\
\hline Excess heat & $\begin{array}{l}\text { The accumulation of temperature } \\
\text { above a threshold (summer } \\
\text { maximum }+1^{\circ} \mathrm{C} \text { ) is a standard } \\
\text { model to predict coral bleaching, } \\
\text { assessed as degree heating weeks } \\
\text { (DHWs) }\end{array}$ & $\begin{array}{l}\text { Hoegh-Guldberg } \\
\text { (1999), Frieler } \\
\text { et al. (2013) }\end{array}$ & $\begin{array}{l}\text { Maximum } \\
\text { DHWs }\end{array}$ & $\begin{array}{l}\text { Maximum DHWs during } 90 \mathrm{~d} \\
\text { prior to survey date (Eq. 2) }\end{array}$ & $0-17.2$ \\
\hline $\begin{array}{l}\text { Early acute } \\
\text { temperature } \\
\text { acclimation }\end{array}$ & $\begin{array}{l}\text { Early exposure to warm water can } \\
\text { acclimate corals to subsequent } \\
\text { extreme temperature anomalies } \\
\text { and reduce bleaching }\end{array}$ & $\begin{array}{l}\text { Pandolfi et al. } \\
\text { (2011) }\end{array}$ & $\begin{array}{l}\text { Degree heating } \\
\text { days (DHDs) } \\
\text { (Maynard } \\
\text { et al. 2008) }\end{array}$ & $\begin{array}{l}\text { Cumulative sum of DHDs }>1{ }^{\circ} \mathrm{C} \\
\text { threshold in the first } 60 \mathrm{~d} \text { of } \\
\text { the } 90 \mathrm{~d} \text { period prior to survey } \\
\text { date (Eq. 4) }\end{array}$ & $0-60$ \\
\hline \multirow[t]{4}{*}{$\begin{array}{l}\text { Extreme } \\
\text { warm } \\
\text { temperatures }\end{array}$} & \multirow[t]{4}{*}{$\begin{array}{l}\text { Reefs experiencing more frequent, } \\
\text { more extreme, or more variable } \\
\text { warm extreme events will deplete } \\
\text { energy reserves and increase } \\
\text { the severity of bleaching }\end{array}$} & \multirow[t]{4}{*}{$\begin{array}{l}\text { McClanahan } \\
\text { et al. (2007) }\end{array}$} & $\begin{array}{l}\text { High spell } \\
\text { events }\end{array}$ & $\begin{array}{l}\text { Total number of temperature } \\
\text { events that exceed the } 90^{\text {th }} \\
\text { quantile of temperatures, } \\
\text { where events }<5 \text { d apart are } \\
\text { considered the same event }\end{array}$ & $0-4$ \\
\hline & & & $\begin{array}{l}\text { High spell } \\
\text { duration, days }\end{array}$ & $\begin{array}{l}\text { Average duration of high spell } \\
\text { events }\end{array}$ & $0-91$ \\
\hline & & & $\begin{array}{l}\text { High spell } \\
\text { peak, }{ }^{\circ} \mathrm{C}\end{array}$ & $\begin{array}{l}\text { Average temperature of high } \\
\text { spell events }\end{array}$ & $27-31$ \\
\hline & & & $\begin{array}{l}\text { High spell rate } \\
\text { of rise, }{ }^{\circ} \mathrm{C} \mathrm{d}^{-1}\end{array}$ & $\begin{array}{l}\text { Average rate of daily temper- } \\
\text { ature rise during high spell } \\
\text { events }\end{array}$ & $0-0.32$ \\
\hline \multirow[t]{2}{*}{$\begin{array}{l}\text { Coral } \\
\text { community } \\
\text { composition }\end{array}$} & \multirow[t]{2}{*}{$\begin{array}{l}\text { Community composition can } \\
\text { influence overall bleaching } \\
\text { severity and mortality }\end{array}$} & \multirow[t]{2}{*}{$\begin{array}{l}\text { Hoegh-Guldberg } \\
\text { (1999), } \\
\text { McClanahan } \\
\text { et al. (2001) }\end{array}$} & $\begin{array}{l}\text { Coral } \\
\text { community } \\
\text { composition }\end{array}$ & $\begin{array}{l}\text { Multivariate index of coral } \\
\text { community composition } \\
\text { based on a correspondence } \\
\text { analysis }\end{array}$ & -1.79 to 1.33 \\
\hline & & & $\begin{array}{l}\text { Coral } \\
\text { community } \\
\text { susceptibility }\end{array}$ & $\begin{array}{l}\text { A weighted score of the relative } \\
\text { abundance multiplied by } \\
\text { bleaching sensitivity in } 2016\end{array}$ & $18.9-36.7$ \\
\hline Depth & $\begin{array}{l}\text { Deeper reefs have less surface } \\
\text { irradiation and potentially cooler } \\
\text { waters }\end{array}$ & $\begin{array}{l}\text { Hoegh-Guldberg } \\
\text { (1999), Graham } \\
\text { et al. (2015) }\end{array}$ & Depth, m & Depth of survey & $1-18$ \\
\hline Habitat & $\begin{array}{l}\text { Lagoons and reef flats can have } \\
\text { warmer more variable environ- } \\
\text { ments with more potential for } \\
\text { acclimation }\end{array}$ & $\begin{array}{l}\text { McClanahan \& } \\
\text { Maina (2003) }\end{array}$ & Habitat & $\begin{array}{l}\text { Habitat was classified as: reef } \\
\text { slope, reef crest, reef flat, } \\
\text { lagoon or back reef, reef } \\
\text { channel, or submerged bank }\end{array}$ & $\begin{array}{l}\text { Bank, } \\
\text { channel, } \\
\text { crest, flat, } \\
\text { lagoon, slope }\end{array}$ \\
\hline Management & $\begin{array}{l}\text { No-take marine reserves reduce } \\
\text { destructive fishing practices that } \\
\text { may promote life histories sensitive } \\
\text { to thermal disturbances }\end{array}$ & $\begin{array}{l}\text { Kleypas et al. } \\
(2008)\end{array}$ & Management & $\begin{array}{l}\text { Management was classified as } \\
\text { open access (fished), restricted } \\
\text { (some gear or access restric- } \\
\text { tions), or no-take (full restriction } \\
\text { on fishing with high compliance) }\end{array}$ & $\begin{array}{l}\text { Open, } \\
\text { restricted, } \\
\text { no-take }\end{array}$ \\
\hline
\end{tabular}


2019) that multiples the relative abundance of colonies in each of the 7 categories $c 0$ to $c 6$ by an increasing factor (from 0 to 6 ), so that more severe bleaching/mortality categories result in a higher bleaching intensity than observations having more pale or less bleached colonies:

Bleaching intensity $=$

$\underline{([0 \times c 0]+[1 \times c 1]+[2 \times c 2]+[3 \times c 3]+[4 \times c 4]+[5 \times c 5]+[6 \times c 6]}$

Both of these metrics produced similar results and both provide simple, repeatable, and comparable methods to quantify bleaching. The bleaching intensity measure is more resolved, spreading sites at low bleaching levels, and resulted in better site distinctions; therefore, bleaching intensity was used rather than percent bleached as the response factor in subsequent analyses. On each survey, we evaluated total bleaching intensity of each observed genus.

To evaluate coral community composition, we estimated the relative abundance of genera from each survey as the number of observed colonies divided by the total number of colonies. We examined a number of similarity and cluster methods and chose Ward's hierarchical cluster analysis, which minimized the variance of dissimilarities of the Bray-Curtis method. This method identified 6 unique clusters of coral communities. We applied a canonical correspondence analysis (CA) ordination to distinguish the taxa that differentiated the cluster groups, and the association with significant environmental factors identified from the modeling. From the ordination, we observed a strong gradient from Acropora- to massive Poritesdominated communities along the first CA axis (CA1).

For each site, we used its CA1 value as a covariate of community composition. This covariate helped to distinguish sites based on their taxonomic composition. From taxa-specific observations compiled for the western Indian Ocean during warm years, bleaching in 2016 did not correlate well with past observations. Specifically, we found that previously resistant taxa bleached more and sensitive taxa bleached less than in previous years (McClanahan et al. 2007). Thus, we used the CA1 covariate to account for the historical bleaching observations that coral communities dominated by Acropora were more sensitive to bleaching than communities dominated by massive and submassive taxa, such as Porites and faviids (Hoegh-Guldberg 1999, McClanahan et al. 2007). The site's susceptibility to bleaching was calculated by multiplying the bleaching intensity for each taxon in 2016 by the number of individuals of that taxon, and summing for all taxa.

\subsection{Temperature and site covariates}

At each location, we evaluated a number of geographic, environmental, habitat, and fisheries management variables and calculated a suite of SST characteristics to determine how thermal stress metrics differentially affect corals (Table 1). Excess thermal stress is a commonly used model to predict coral bleaching (Donner et al. 2005, McClanahan et al. 2007, Eakin et al. 2010). To assess thermal stress, we downloaded the daily degree heating weeks (DHWs) product from the NOAA Coral Reef Watch website (https://coralreefwatch.noaa.gov/product/5km/). The DHWs product accumulates temperature anomalies exceeding the maximum of the monthly mean (MMM) SST for a given $5 \mathrm{~km}$ grid over a rolling 12 wk period (Strong et al. 2004, Eakin et al. 2010, Liu et al. 2014). Based on the assumption that anomalies $<1^{\circ} \mathrm{C}$ SST are insufficient to cause stress to corals, only anomalies $\geq 1^{\circ} \mathrm{C}$ were used:

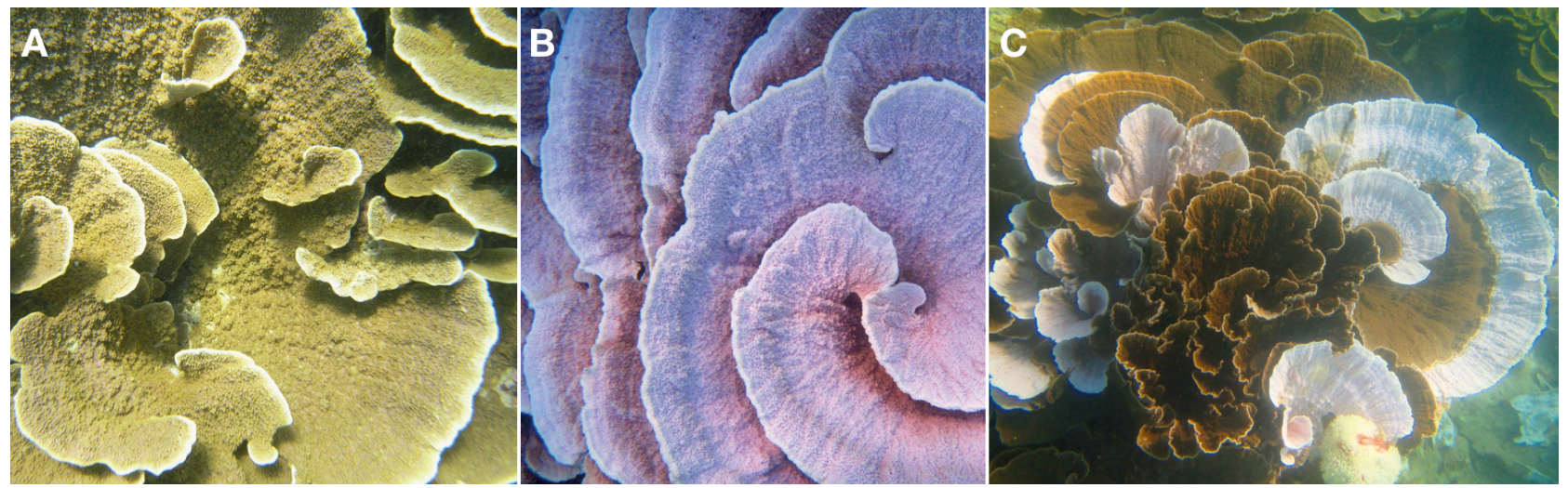

Fig. 1. Examples of (A) normal, (B) pale, and (C) partially bleached corals in the genus Montipora 


$$
\begin{aligned}
\mathrm{HS}= & \left\{\begin{array}{r}
\mathrm{SST}_{\text {daily }}-\mathrm{MMM}, \mathrm{SST}_{\text {daily }}>\mathrm{MMM} \\
0, \mathrm{SST}_{\text {daily }} \leq 0
\end{array}\right. \\
& \mathrm{DHWs}=\frac{1}{7} \sum_{i=1}^{84}\left(\mathrm{HS}_{i}, \text { if } \mathrm{HS}_{i}>1^{\circ} \mathrm{C}\right)
\end{aligned}
$$

where HS refers to daily anomalies $>1$ accumulated over a $12 \mathrm{wk}$ (84 d) period (Strong et al. 2004).

In addition, we also calculated the maximum and average DHWs during the $90 \mathrm{~d}$ prior to each survey. To characterize the acute thermal environment and relate it to observed bleaching, we downloaded SST time series for $90 \mathrm{~d}$ prior to the date of sampling for each survey (NOAA Coral Reef Watch). These were gap-filled daily SST data based on NOAA AVHRR satellite observations at a resolution of $\sim 5 \times 5 \mathrm{~km}$ grid cells. To assess chronic thermal stress, we used the CRW $50 \mathrm{~km}$ grids data set to calculate hotspots, defined as positive SST anomalies referenced to the MMM SST climatology (i.e. MMM climatology) (Strong et al. 2004). We then calculated degree heating months (DHMs) as the sum of hotspots $\geq 1^{\circ} \mathrm{C}$ and cumulatively aggregated cells with DHMs $>1{ }^{\circ} \mathrm{C}$ for the period 1985-2015 to derive the cumulative

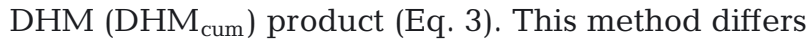
from DHMs as described by Barton \& Casey (2005), where DHMs were calculated as the accumulation of monthly hotspots $>0^{\circ} \mathrm{C}$ at a location over a rolling 3 mo time period. The thermal stress map (see DHM $_{\text {cum }}$ in Fig. 2) is based on the $50 \mathrm{~km}$ resolution data that extends back to 1982 .

Monthly hotspots (HSm, where monthly anomalies $>1$ ) were accumulated for the period 1985-2015:

$$
\begin{gathered}
\mathrm{HSm}=\left\{\begin{array}{r}
\mathrm{SST}_{\text {monthly }}-\mathrm{MMM}_{,} \mathrm{SST}_{\text {monthly }}>\mathrm{MMM} \\
0, \mathrm{SST}_{\text {monthly }} \leq 0
\end{array}\right. \\
\mathrm{DHM}=\sum_{i=1}^{i=n}\left(\mathrm{HSm}_{i}, \text { if }_{\left.\mathrm{HS}_{i}>1^{\circ} \mathrm{C}\right)}\right.
\end{gathered}
$$

where $n$ is the number of months.

The SST $90 \mathrm{~d}$ time series were evaluated for similarity among the 226 sites using the Permutation Distribution Cluster method that differentiates time series based on the time step variation (R package 'pdc' v.1.03; Brandmaier 2015). This method produced 6 significant 90 d clusters for 2016 and 13 significant 90 d clusters for 1985-2015 SST. We present associations of the 6 significant coral community clusters with the 6 and 13 statistically significant SST clusters ( $p$ <.01) (see Fig. 2). The $90 \mathrm{~d}$ clusters were ordered by their mean SSTs. The 1985-2015 clusters were ordered, highest to lowest, by the strength of fit of the environmental variables with coral cover. The strongest variable was SST skewness followed subordinately by $\mathrm{DHM}_{\text {cum }}$, kurtosis, mean SST, the multivariate 'global stress model' metric, and climate exposure. Clusters were described by their main attributes in descending order of importance.

Recent studies have suggested that SST distributions prior to bleaching may expose corals to prestress acclimation and act as a protective mechanism to reduce subsequent bleaching (Ainsworth et al. 2016, McClanahan et al. 2019). To describe the accumulation of heat stress during the period prior to bleaching, we calculated degree heating days (DHDs) as the summed positive deviations of daily SST from the MMM (Eq. 4) (Maynard et al. 2008). DHDs were accumulated during the first $60 \mathrm{~d}$ of the 90 d SST time series:

$$
\text { DHDs }=\sum_{i=1}^{60}\left(\mathrm{SST}_{\text {daily }}-\mathrm{MMM}\right)
$$

As a further test of this hypothesis, we evaluated SST distribution for bimodality during the $90 \mathrm{~d}$ prior to each bleaching survey. Bimodal probability distributions have 2 unambiguous peaks of SSTs, cool and hot, separated by an abrupt boundary, in contrast to unimodal (Gaussian) distributions of SST that fall along a normal distribution from cool to hot. To quantify the bimodality characteristics of SST distributions at each site, we computed 3 metrics: a bimodality coefficient, a bimodality peak proportion, and a dip statistic (Ellison 1987, Freeman \& Dale 2013). The bimodality coefficient is the presence of bimodal distributions with a range of $[0,1]$, where a value $>0.55$ suggests bimodality; the maximum value of one ('1') can only be reached when the distribution is composed of 2 separate point masses. The bimodality peak proportion describes the ratio between the 2 peaks, where values $>0$ indicate that the amplitude of the hot peak dominates the cool peak. In all of our SST time series cases, the first peak was smaller than the second peak (after which corals were sampled). Consequently, the peak proportion statistic will increase as the later SST peak becomes larger than the earlier peak. The dip statistic also measures bimodality by measuring the maximum distance between the empirical versus a unimodal distribution and can account for bimodality when the bimodality coefficient does not (Hartigan \& Hartigan 1985). Bimodality metrics reflect probability distributions and not always the temporal patterning within a time series. These metrics were calculated using the 'modes' package in R (R Core Team 2017).

To describe the characteristics of extreme warm and cold SSTs, we used the 'hydrostats' package in R 
to calculate the frequency and duration of high and low 'spells' during the $90 \mathrm{~d}$ time series. 'Spells' are defined as a period of extreme SST characteristics that were greater than or lower than defined high and low SST thresholds, respectively. High SST thresholds were defined as the MMM, which is a baseline of the warmest summer month during the last $30 \mathrm{yr}$. We defined the SST threshold at the $10^{\text {th }}$ percentile of SST time series during the $90 \mathrm{~d}$ period before sampling. Periods between spells of $<5 \mathrm{~d}$ were 'in spell' for the purpose of calculations. After identifying the high and low spells, we calculated factors to describe the frequency, duration, and rate of SST change within extreme spell events for both warm and cold extreme events.

\subsection{Data analyses}

The relationships between all environmental factors were evaluated and were found to be complex and not strongly correlated, which indicated independence among the variables. We used generalized linear mixed effect models (GLMMs) with a random intercept to examine the direction and magnitude of the relationships between the environmental and site covariates with taxon-specific bleaching intensity. To account for hierarchical structure, we defined 'location' as a random effect in our models as an alternative hierarchical structure to the use of the nation. Defining a location's grouping accounted for more appropriate geomorphology and environmental groupings of survey sites, compared to national socioeconomic boundaries. We also included geographic variables of latitude and longitude as covariates in our models to account for the unbalanced longitudinal sampling. As our objective was to assess bleaching across as many different habitats and reef environments as possible, geographical variables were included as covariates to account for other putative drivers that may vary along the geographic gradient across the studied sites (e.g. biogeography, biodiversity, or symbiont community composition).

Before applying statistical models, we determined that the dependent variable (i.e. bleaching intensity) fell into the open interval $[0,1]$; consequently, we chose beta regression models for the analyses (Zimprich 2010). Additionally, we checked for collinearity among covariates by constructing all possible combinations of the covariates (up to 3 covariates with interactions), and examining the variance inflation factor (VIF) for each model using the 'usdm' package in R. We used VIF > 1.5 as a threshold to determine collinearity (Graham 2003), and removed any models that contained collinear variables above this threshold. A subset of 48980 combinations of independent predictor variables were then used to construct GLMMs using the template model builder ('glmm$\mathrm{TMB}^{\prime}$ ) package in R (Brooks et al. 2017). Regression coefficients are sensitive to the scale of the inputs. To aid in their interpretation, we placed the input variables on a common scale by dividing each numeric covariate by 2 times its standard deviation prior to analyses (Gelman 2008). The resulting regression coefficients could then be directly compared.

Models were run in a model selection framework and compared using Akaike's information criterion adjusted for small sample sizes $\left(\mathrm{AIC}_{\mathrm{C}}\right)$ and Akaike weights to represent the relative support for each model. To discriminate more thoroughly among covariates and the mechanisms postulated as important for bleaching, we selected a top model set $\left(<2 \Delta \mathrm{AIC}_{\mathrm{C}_{1}}\right.$ $\mathrm{n}=3$ ) and performed $\mathrm{AIC}_{\mathrm{C}}$-weighted model averaging across the top model set to calculate standardized coefficients (with $95 \% \mathrm{CI}$ ), adjusted standard errors and associated $t$-statistics and $\mathrm{p}$-values for the set of predictors represented in the top model set. We repeated this procedure using the average bleaching intensity of each of the 30 dominant coral taxa as the response variable in the model. After calculating model-averaged parameters for each taxon, we also wanted to evaluate taxa that shared similar responses from the modeling outputs. We used an 'unweighted pair group method with arithmetic mean' average cluster analysis based on a Gower dissimilarity matrix of model-averaged coefficients to determine the clustering structure of taxon coefficients.

To validate the top models, we visually evaluated plots of the model residuals versus fitted values, and constructed Moran's I similarity spline correlograms from the residuals of the fitted models to test for bias from spatial autocorrelation (Zuur et al. 2009). Additionally, we used Mantel tests (Mantel 1967, Legendre \& Fortin 1989) to confirm the lack of spatial autocorrelation between the Pearson residuals of the model averages and the lag distance (in $\mathrm{km}$ ) between sites, and found that the overall correlation coefficient for the model was low. We used the 'ncf' package in R for estimating Moran's $I$ and Mantel tests (Bjørnstad 2013, R Core Team 2017). To evaluate the predictive ability of the top models of bleaching intensity, we applied simple bootstrapping using the 'boot' package in R (Harrell 2001). This involved creating 100 resamples with replacement from the original data of the same size and applying the models to the resample, then using the model to predict 
the values of the full set of original data and calculating the $\mathrm{R}^{2}$ goodness-of-fit statistic by comparing the predicted value to the actual value. All analyses were run in R v.3.3.4 (R Core Team 2017).

\section{RESULTS}

\subsection{Bleaching and coral communities}

Evaluation of the 226 reef sites revealed that SST anomalies and bleaching responses were spatially patchy, and historical and 2016 temperature anomalies were not strongly correlated (Fig. 2). There was high bleaching in 2016 with $51 \%$ of the coral colonies classified as severely bleached (Table S2).

Based on the taxa and their abundance, coral communities clustered into 6 groups that were broadly distributed in our Indo-Pacific sites (Fig. 2A). Most taxa and communities had unique responses to acute thermal stress (Fig. 3A,B) and models with several variables were selected as superior to single-variable models (Table 2). Community clusters differed in their taxonomic composition and attributes, such as their susceptibility to bleaching, total coral cover, and numbers of taxa (Figs. 3B \& 4, Table S3). The first canonical correspondence axis (CA1) distinguished sites predominantly by dominance of either massive Porites or Acropora (Fig. 3C). The second CA axis (CA2) separated a community of corals, namely Cluster 3, found almost exclusively in southern Kenya and northern Tanzania, that had high dominance of the reef-builder taxa Galaxea astreata and branching Porites, but also sub-dominance of Acropora, Fungia, and Seriatopora (Table S3).

\subsection{Temperatures and associations with corals}

Based on 90 d SST trajectories, acute thermal metrics also clustered into 6 groups that varied primarily along the mean SST, average high SST peak, and low SST duration (Fig. 2C, Table 3). Long-term (1985-2015) SST patterns clustered into 13 groups that varied primarily by SST skewness ranging from warm skew (Clusters 1-5) to cold skew (Clusters 9-13), and little skew in Clusters 6, 7, and 8 (Fig. 2D, Table 4). Coral cover was significantly predicted by 1985-2015 SST skewness, kurtosis, and cumulative DHMs (Fig. 5). Notably, the best-fit relationships with skewness and cumulative DHMs were nonlinear and unimodal, indicating that both cold or warm skewness or low or high DHMs were associ- ated with reduced coral cover. The kurtosis relationship with coral cover was negative and linear, suggesting that coral cover declined as SST distributions became centralized and thick tailed.

Short- and long-term SST time series were significantly but only moderately associated with each other at sites, being somewhat stronger when comparing monthly $\left(r^{2}=0.47\right)$ with daily SSTs $\left(r^{2}=0.37\right)$ (Table 5A). Monthly and daily long-term SST clusters were, however, quite strongly associated $\left(\mathrm{r}^{2}=0.77\right)$ (Table 5B). Thus, sites were not consistently exposed to the same short- and long-term SST stresses. As expected, short-term thermal time series were significantly but weakly associated with the 6 community clusters (Table 5C, Fig. 2C). However, the better fit to the long-term temperature stress from 1985-2015 indicated that sites in coral community Clusters 5 and 6 dominated by massive Porites were associated with historical high warm-water skewness and centralized kurtosis (Table 5C, Fig. 2D). Acropora-dominated communities were broadly distributed but were most common where mean SSTs were cooler, background SST variation was higher, and in locations that experienced low acute periodic warmwater stress (Fig. 2D). The Kenyan-Tanzanian Galaxea/branching Porites/mixed community Cluster 3 was associated with low thermal stress and low to medium cumulative DHMs. Based on temperature distributions alone, these patterns suggest 3 major groupings of community and life history associations: (1) Acropora dominance in cooler, high variation SST, low frequency of extreme warm conditions; (2) massive Porites in warmer, low variation, periodically warm stressful conditions; and (3) a mix of Galaxea/ branching Porites/other subdominant taxa in more stable thermal environments.

\subsection{Taxa-specific bleaching}

Taxon-specific bleaching patterns in 2016 indicated novel responses compared to historical reports during thermal anomalies. For example, Acroporadominated sites were associated with less bleaching than sites dominated by massive Porites (Fig. 3B). Higher bleaching along the massive Porites portion of the CA1 axis was also associated with higher historical mean SSTs and SST bimodality. The Galaxea/branching Porites community, or axis CA2, was distinguished by larger mean high and low spell durations and variation in the high spell peak. The complexity of these responses was also evident in the results of the model selections for 

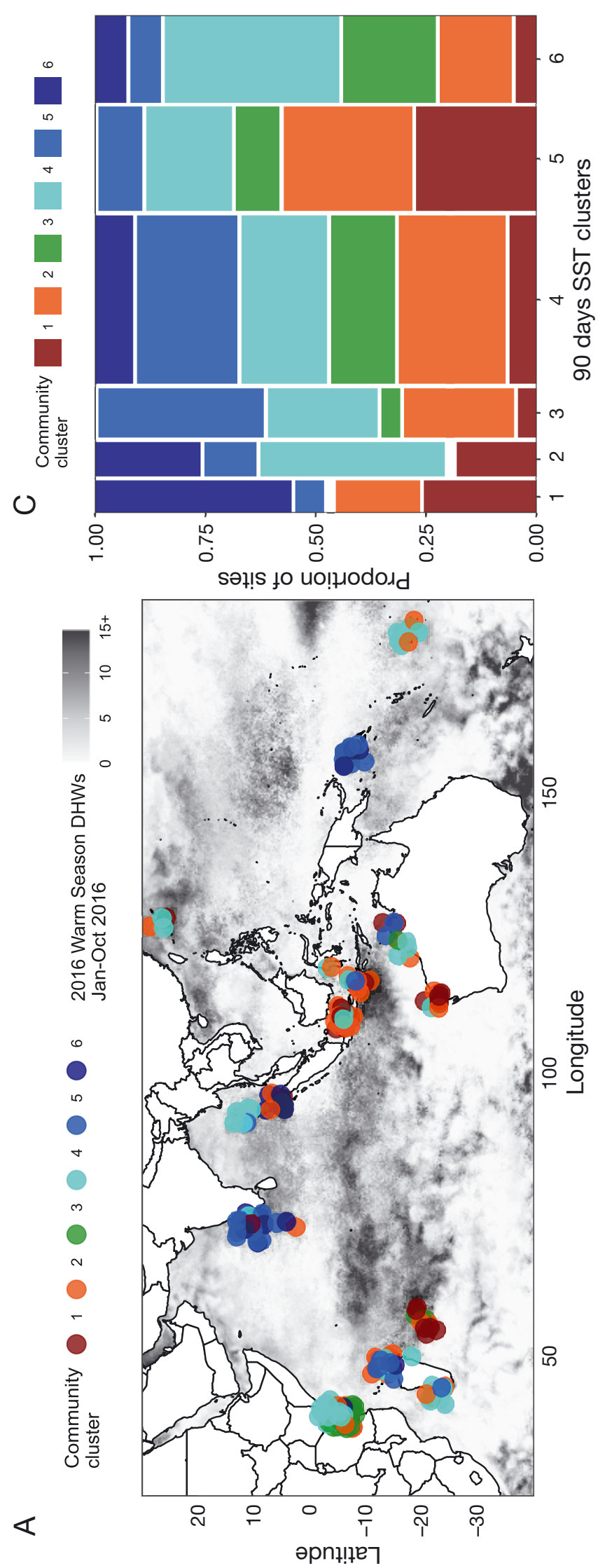

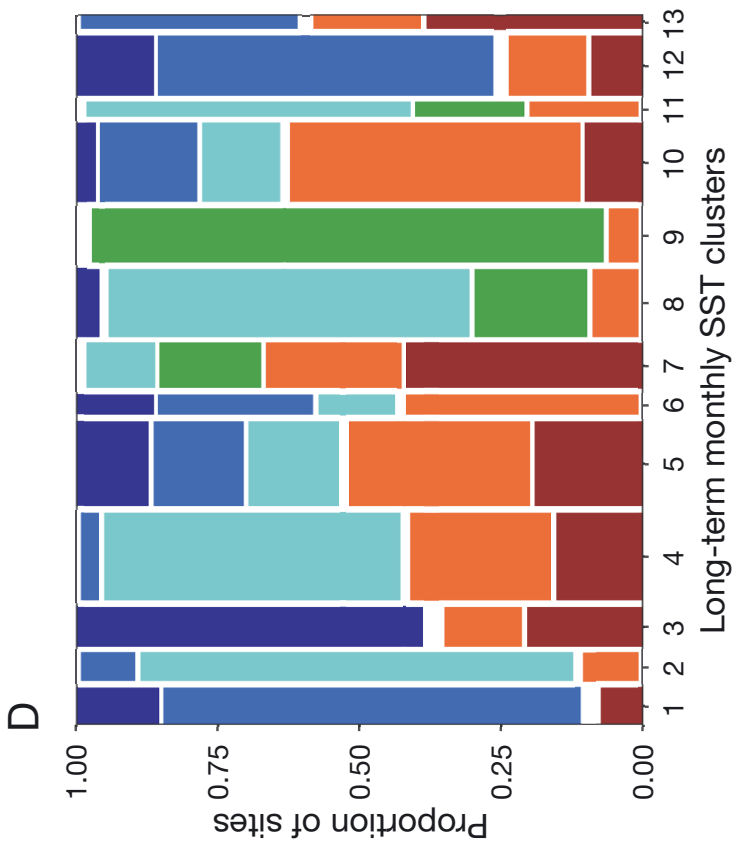

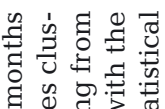

a s.

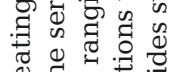

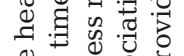

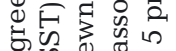

क्ष

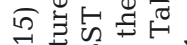

iิ 0

1 일

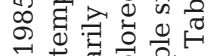

의 웅 :

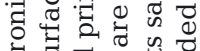

द्व

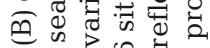

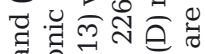

(n)

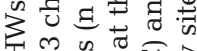

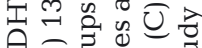

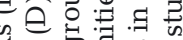

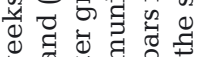

3 \% 릉

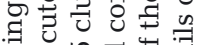

당

웅ㅎㅇ

U

S. 0

舟

政的的

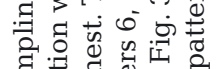

궁 हो

s.

웜워

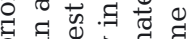

क

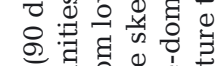

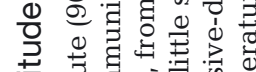

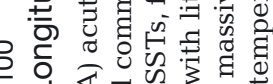

ए

o :

웜

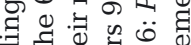

类

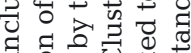

घ.

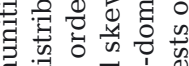

:-7 0 엉

द $0 \mathrm{~d}$

둥 3

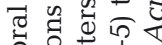

o. 을

o

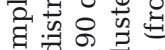

议

त $\sum^{n}$

的离 

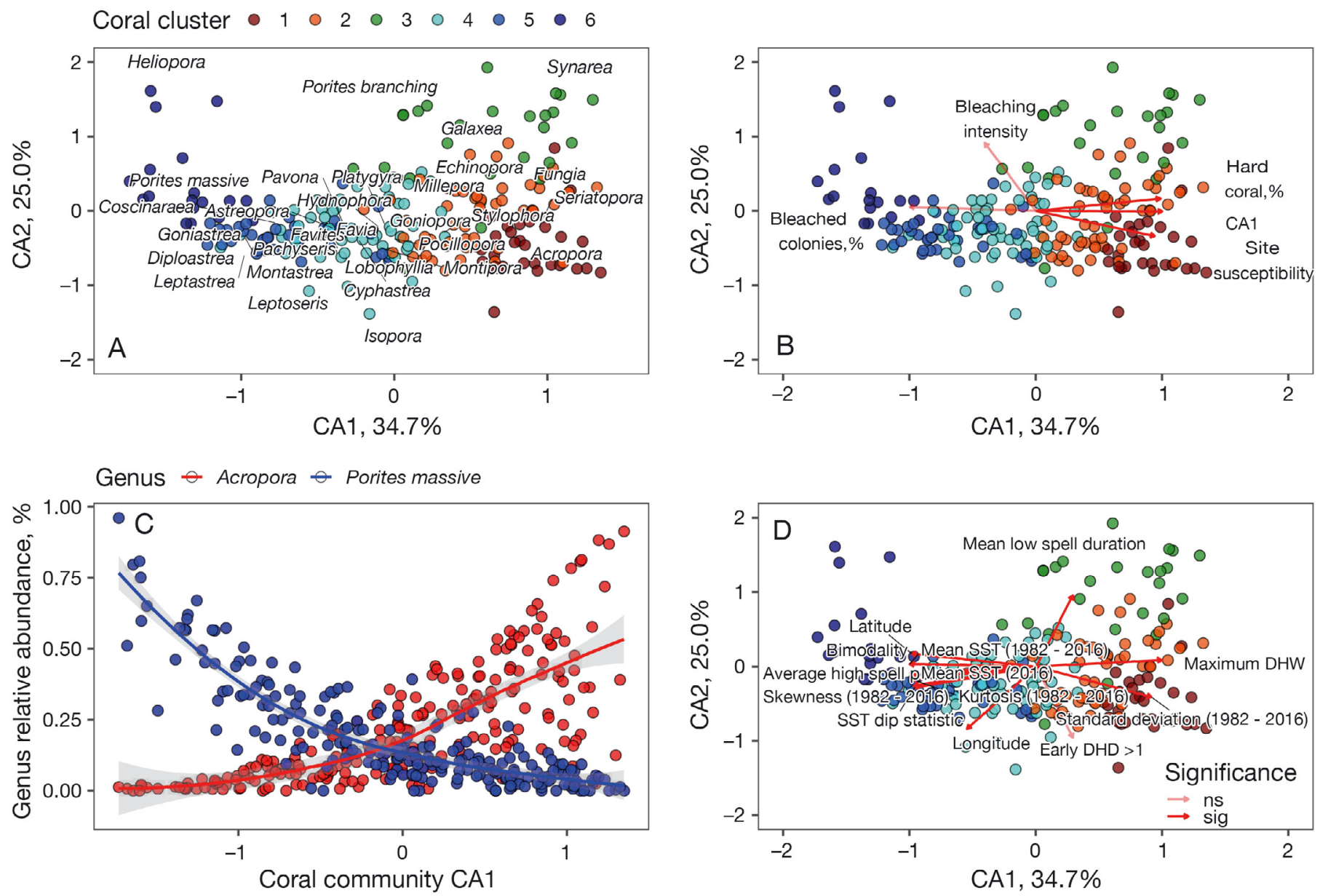

Fig. 3. Multivariate analysis of coral communities with site and temperature exposure. (A) Canonical correspondence analysis (CA) of the dominant 30 coral taxa, (B) associations of these communities with hard coral cover, community bleaching susceptibility, and observed bleaching in 2016, (C) relative dominance of Acropora and massive Porites in the 6 coral communities along this first CA axis for the 226 reef sites, and (D) acute (90 d 2016 warm season) and chronic (1985-2016 monthly) sea surface temperature (SST) variables associated with 6 coral community clusters. The first 2 CA axes explain $59.7 \%$ of variation in coral communities. Significant ('sig'; $\alpha<0.05$ ) and non-significant ('ns') predictors of bleaching intensity are indicated. DHWs: degree heating weeks. The grey shading in (C) shows $95 \%$ confidence intervals

the dominant 18 coral taxa, where longitude, bimodality, high spell peaks and duration, community susceptibility, and their interactions were the major correlates of bleaching (Fig. 6). Finally, plotting the by-taxon bleaching responses in the Indian Ocean prior to, and during 2016 showed high scatter and a weak linear relationship (Fig. 7). Nevertheless, while statistically significant, the relationship was considerably lower than a 1-to-1 expectation of a constant by-taxon response to bleaching over time. All genera experienced higher levels of bleaching in 2016 compared to the pre2016 compilation of warm responses (intercept at $23.7)$ but the weak slope (0.37) suggests that historically sensitive corals bleached relatively less than tolerant taxa in 2016. The higher intercept is likely a result of making bleaching observations in years with less thermal stress than 2016.

Taxon-specific evaluations of single, multiple and interacting environmental variables indicated a number of significant relationships and the importance of geography (Fig. 6). For these by-taxon analyses, there was a lack of consistent responses for specific thermal stress metrics. The most frequently significant metric was average high SST peak, which was positively associated with bleaching for 4 taxa, particularly strong for massive Porites, but negative for one stress-resistant genus (Hydnophora). Maximum DHWs was only positively associated with bleaching for Echinopora. Many multiple and interacting thermal stress, geography, and habitat variables were positively and negatively associated with bleaching 
Table 2. Results and ranks of multi-model inference statistics for the dominant coral taxa. Ranks and fit of model outputs results of the top models of 1394 options where 22 factors and their interactions were tested for associations with the bleaching intensity metric at the study sites during warm seasons in 2016. For comparison, results of the single factors that were present in the best models and all factors being tested are included. Ranks are based on Akaike's information criterion adjusted for small sample sizes (AIC ${ }_{C}$ ), with differences from the best model shown $(\Delta \mathrm{AIC})$ along with Akaike weights $\left(w_{i}\right)$. NS: not significant; sig: $\mathrm{p}<0.01$

\begin{tabular}{|c|c|c|c|c|c|c|c|c|c|}
\hline \multicolumn{2}{|r|}{ Models } & df & logLik & $\mathrm{AIC}_{\mathrm{C}}$ & $\Delta \mathrm{AIC}$ & $w_{i}$ & $\begin{array}{l}\text { Coeffi- } \\
\text { cient }\end{array}$ & $\begin{array}{l}\text { Signifi- } \\
\text { cance }\end{array}$ & $\mathrm{R}^{2}$ \\
\hline \multicolumn{10}{|c|}{ Set 1: Top models set $\left(<2 \mathrm{AIC}_{\mathrm{C}}\right)$} \\
\hline 2 & $\begin{array}{l}\text { Bleaching intensity } \sim \text { longitude } \times \text { average high spell peak } \times \\
\text { mean low spell duration }\end{array}$ & 10 & 246.1 & -471.2 & 1.3 & 0.3 & & & 0.71 \\
\hline 37 & Average high spell peak & 4 & 225.8 & -443.4 & 29.1 & 0.0 & 1.04 & sig & \\
\hline 39 & Longitude & 4 & 225.7 & -443.2 & 29.3 & 0.0 & -1.26 & sig & \\
\hline 60 & Mean low spell duration & 4 & 224.3 & -440.5 & 32.0 & 0.0 & 0.22 & NS & \\
\hline & Bimodality & 4 & 223.4 & -438.5 & 33.9 & 0.0 & 0.52 & $\operatorname{sig}$ & \\
\hline \multicolumn{10}{|c|}{ Set 3: Top models set for Acropora $\left(<2 \mathrm{AIC}_{\mathrm{C}}\right)$} \\
\hline 1 & $\begin{array}{l}\text { Bleaching intensity } \sim \text { depth } \times \text { coral community susceptibility } \times \\
\text { mean duration of high spell events }\end{array}$ & 10 & 215 & -410.5 & 0 & 0.4 & & & \\
\hline 1 & $\begin{array}{l}\text { Bleaching intensity } \sim \text { longitude } \times \text { average high spell peak } \times \\
\text { coral community composition }\end{array}$ & 10 & 412.5 & -804.0 & 0 & 0.41 & & & \\
\hline 2 & $\begin{array}{l}\text { Bleaching intensity } \sim \text { bimodality dip statistic } \times \text { average } \\
\text { high spell peak } \times \text { coral community composition }\end{array}$ & 10 & 411.7 & -802.5 & 1.52 & 0.19 & & & \\
\hline \multicolumn{10}{|c|}{ Set 4: Top models set for Galaxea $\left(<2 \mathrm{AIC}_{\mathrm{C}}\right)$} \\
\hline 1 & $\begin{array}{l}\text { Bleaching intensity } \sim \text { number of high spell events } \times \text { variance } \\
\text { of high spell peak } \times \text { coral community composition }\end{array}$ & 10 & 866.3 & -1711.5 & 0 & 0.04 & & & \\
\hline 2 & $\begin{array}{l}\text { Bleaching intensity } \sim \text { coral community susceptibility } \times \\
\text { mean duration of high spell events }\end{array}$ & 10 & 861.8 & -1711.1 & 0.38 & 0.03 & & & \\
\hline 3 & $\begin{array}{l}\text { Bleaching intensity } \sim \text { mean duration of high spell events } \times \\
\text { mean low spell duration } \times \text { coral community composition }\end{array}$ & 10 & 866.1 & -1711.1 & 0.42 & 0.03 & & & \\
\hline
\end{tabular}

responses. Again, when evaluating the interactions between environmental variables we found a high diversity of responses and little indication of shared bleaching responses among taxa (Fig. 8).

\section{DISCUSSION}

Some previous and recent large-scale studies have found good associations between bleaching and DHWs at regional scales (McClanahan et al. 2007, Eakin et al. 2010, Hughes et al. 2017, Sully et al. 2019). These reefs were often dominated by histori- cally thermally sensitive genera, such as Acropora. However, where sites have been studied over time, there is an ongoing replacement of sensitive corals and associated symbiotic taxa by weedy and stresstolerant coral taxa and heat-resistant symbionts (Darling et al. 2013, Edmunds et al. 2014, McClanahan et al. 2014, Palumbi et al. 2014). Consequently, the overall bleaching response on many reefs should change over time due to a combination of differential survival of genotypes, changing species dominance, and acclimation to thermal stress (Grottoli et al. 2014, McClanahan 2017). Our findings show that coral taxa respond differentially to many possible thermal stres- 

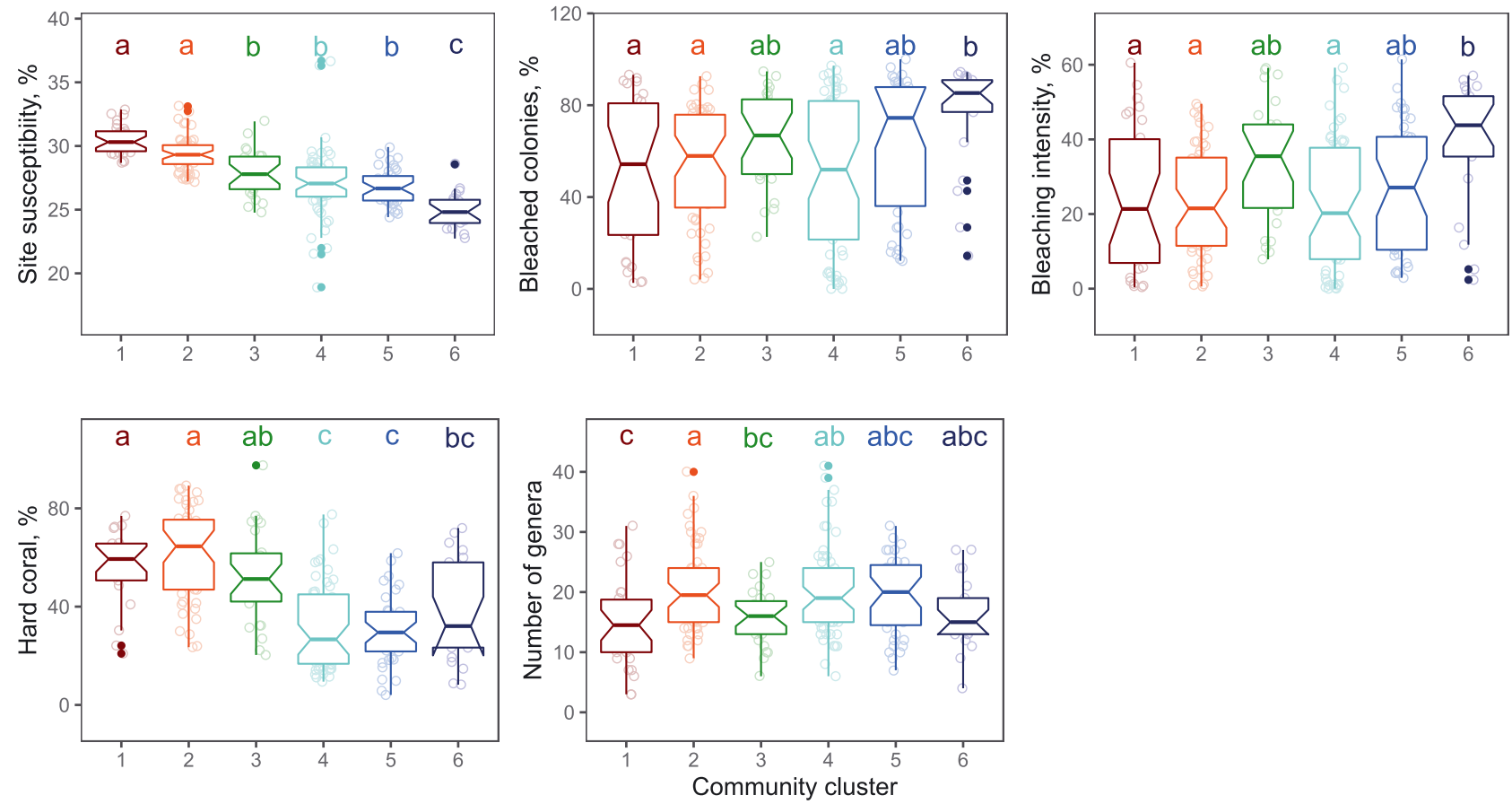

Fig. 4. Ecological attributes and bleaching responses across the 6 community clusters in 2016 (see Fig. 2A for community-color associations), shown as box plots of site susceptibility, percent bleaching, bleaching intensity, hard coral cover and taxonomic richness. Letters indicate differences between cluster groups where groups that are not different share the same letters $(\alpha<0.05)$ based on Tukey post hoc pairwise comparisons. Site susceptibility is the predicted response of the coral community to bleaching in 2016 based on the weighted response of each taxon. Bars: medians; boxes: interquartile range (IQR); whiskers: min./max. values $<1.5 . \times \mathrm{IQR}_{\text {; }}$ colored circles: outliers

ses and that geography plays an important role in the responses. Thus, cumulative excess heat may have been useful especially for dominant taxa but, on a broad scale as of 2016, it was a poor predictor of coral responses both for the whole community and specific taxa. Part of the poor fit may have been the sometimes weak relationships between in situ and satellite-derived data, but this would only explain some of the variation (McClanahan et al. 2019). Regardless, we propose that in reefs and taxa frequently exposed to thermal stresses, complex or novel stresses will increasingly be needed to activate bleaching in the future. Conversely, reefs that have missed recent thermal stresses and are therefore 'thermally-naïve' should respond strongly to simple thermal anomalies, such as DHWs (Hughes et al. 2017). The ongoing spatial expansion and temporal change of thermal anomalies should be paralleled by succession of coral responses in the wake of the observed geographic thermal expansion and increasing variability (Hughes et al. 2018a, Skirving et al. 2019).

Coral communities appear to be structured by historical temperature patterns. Nevertheless, the weak correspondence between historical and 2016 temper-

Table 3. Short-term or $90 \mathrm{~d}$ acute sea surface temperature (SST) clusters and their descriptors. DHWs: degree heating weeks

\begin{tabular}{|cccccccl|}
\hline $\begin{array}{c}\text { Short- } \\
\text { term SST } \\
\text { cluster }\end{array}$ & $\begin{array}{c}\text { SST } \\
\text { mean (SD) } \\
\left({ }^{\circ} \mathrm{C}\right)\end{array}$ & $\begin{array}{c}\text { Maxi- } \\
\text { mum } \\
\text { DHWs }\end{array}$ & $\begin{array}{c}\text { Dip } \\
\text { statistic }\end{array}$ & $\begin{array}{c}\text { Bi- } \\
\text { modality }\end{array}$ & $\begin{array}{c}\text { High spell } \\
\text { peak }\end{array}$ & $\begin{array}{c}\text { Low spell } \\
\text { duration }\end{array}$ & \multicolumn{1}{c|}{ Cluster descriptions } \\
\hline 1 & $30.4(0.7)$ & 0.05 & 0.04 & 0.56 & 30.6 & 7.6 & Warm-water, low variation, low DHWs \\
2 & $29.6(1.1)$ & 5.8 & 0.05 & 0.58 & 29.8 & 4.4 & Warm-water, high variation, high DHWs \\
3 & $29.5(0.9)$ & 1.8 & 0.04 & 0.47 & 29.6 & 2.7 & Cool-water, low variation, low DHWs \\
4 & $29.4(0.9)$ & 3.2 & 0.04 & 0.53 & 29.6 & 3.8 & Cool-water, low variation, high DHWs \\
5 & $29.4(1.2)$ & 3.1 & 0.04 & 0.55 & 29.6 & 3.8 & Cool-water, high variation, high DHWs \\
6 & $28.4(1.3)$ & 2.6 & 0.04 & 0.53 & 29.1 & 4.3 & Cold-water, high variation, medium DHWs \\
\hline
\end{tabular}


Table 4. Long-term temperature cluster descriptors. Includes value for skewness, cumulative degree heating weeks (DHWs), kurtosis, mean sea surface temperature (SST), global stress model, and climate exposure. Variables are ordered from right to left by the strength of their associations with coral cover

\begin{tabular}{|c|c|c|c|c|c|c|c|}
\hline $\begin{array}{l}\text { Long-term } \\
\text { clusters } \\
\text { (monthly) }\end{array}$ & $\begin{array}{c}\text { Skew- } \\
\text { ness } \\
\left({ }^{\circ} \mathrm{C}\right)\end{array}$ & $\begin{array}{l}\text { Cumu- } \\
\text { lative } \\
\text { DHWs }\end{array}$ & $\begin{array}{c}\text { Kurto- } \\
\text { sis } \\
\left({ }^{\circ} \mathrm{C}\right)\end{array}$ & $\begin{array}{l}\text { SST mean } \\
(\mathrm{SD})\left({ }^{\circ} \mathrm{C}\right)\end{array}$ & $\begin{array}{l}\text { Global } \\
\text { stress } \\
\text { model }\end{array}$ & $\begin{array}{l}\text { Climate } \\
\text { exposure }\end{array}$ & Cluster descriptions \\
\hline 1 & 0.42 & 16.77 & -0.02 & $28.7(0.0)$ & 0.79 & 0.56 & $\begin{array}{l}\text { High warm-temperature skewness, very low cumulative DHWs, } \\
\text { neutral kurtosis }\end{array}$ \\
\hline 2 & 0.35 & 19.15 & 0.33 & $28.7(0.12)$ & 0.82 & 0.77 & $\begin{array}{l}\text { High warm-temperature skewness, low cumulative DHWs, } \\
\text { high positive kurtosis }\end{array}$ \\
\hline 3 & 0.15 & 20.44 & -0.15 & $29.0(0.03)$ & 0.84 & 0.75 & $\begin{array}{l}\text { Medium warm water skewness, low cumulative DHWs, } \\
\text { medium negative kurtosis }\end{array}$ \\
\hline 4 & 0.12 & 22.79 & -1.03 & $26.3(0.78)$ & 0.82 & 0.47 & $\begin{array}{l}\text { Medium warm water skewness, medium cumulative DHWs, } \\
\text { very low negative kurtosis }\end{array}$ \\
\hline 5 & 0.11 & 28.8 & -0.28 & $28.8(0.1)$ & 0.84 & 0.74 & $\begin{array}{l}\text { Medium warm water skewness, medium cumulative DHWs, } \\
\text { medium negative kurtosis }\end{array}$ \\
\hline 6 & 0.07 & 33.44 & -0.14 & $28.7(0.09)$ & 0.88 & 0.73 & $\begin{array}{l}\text { Neutral skewness, high cumulative DHWs, } \\
\text { medium negative kurtosis }\end{array}$ \\
\hline 7 & 0.04 & 28.96 & -1.27 & $25.6(0.44)$ & 0.38 & 0.33 & $\begin{array}{l}\text { Neutral skewness, medium cumulative DHWs, } \\
\text { very low kurtosis }\end{array}$ \\
\hline 8 & 0.03 & 9.04 & -0.80 & $27.0(0.07)$ & 0.9 & 0.68 & $\begin{array}{l}\text { Neutral skewness, very low cumulative DHWs, } \\
\text { low negative kurtosis }\end{array}$ \\
\hline 9 & -0.18 & 13.65 & -1.0 & $27.3(0.03)$ & 0.83 & 0.62 & $\begin{array}{l}\text { Medium cold-water skewness, very low cumulative DHWs, } \\
\text { low negative kurtosis }\end{array}$ \\
\hline 10 & -0.22 & 22.37 & -1.12 & $27.7(0.23)$ & 0.81 & 0.58 & $\begin{array}{l}\text { Medium cold-water skewness, low cumulative DHWs, } \\
\text { very low negative kurtosis }\end{array}$ \\
\hline 11 & -0.50 & 35.6 & -0.96 & $28.2(0.02)$ & 0.94 & 0.79 & $\begin{array}{l}\text { High cold-water skewness, high cumulative DHWs, } \\
\text { low negative kurtosis }\end{array}$ \\
\hline 12 & -0.56 & 52.75 & 0.15 & $29.0(0.47)$ & 0.88 & 0.85 & $\begin{array}{l}\text { High cold-water skewness, very high cumulative DHWs, } \\
\text { medium positive kurtosis }\end{array}$ \\
\hline 13 & -0.67 & 28.31 & -0.56 & $28.4(0.05)$ & 0.96 & 0.87 & $\begin{array}{l}\text { Very high cold-water skewness, medium cumulative DHWs, } \\
\text { medium negative kurtosis }\end{array}$ \\
\hline
\end{tabular}
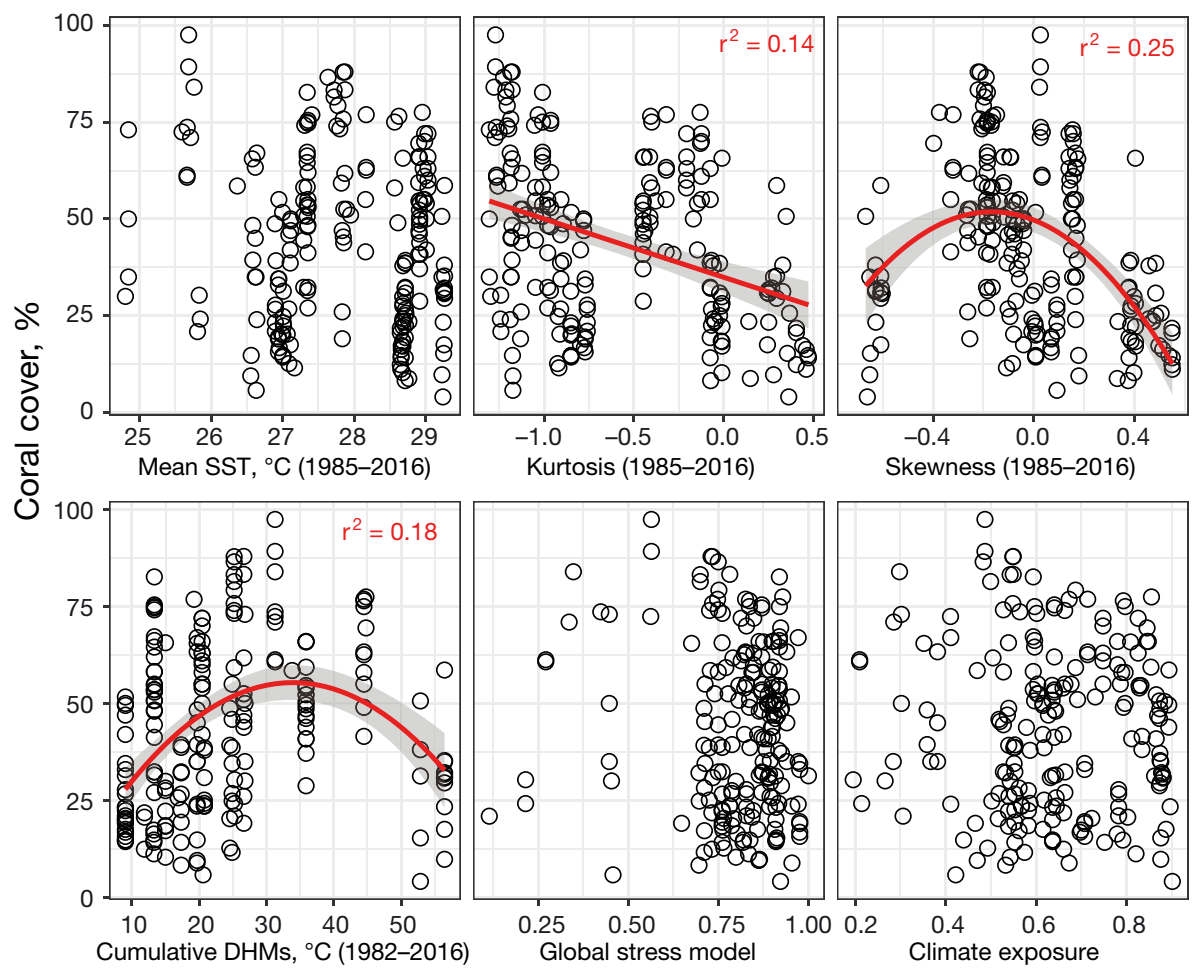

Fig. 5. Relationships between long-term sea surface temperature (SST) characteristics (19852015) and coral cover for 226 sampled sites. The global stress and climate exposure models describe multivariate conditions of climate stress and exposure (i.e. light, temperature, tides, etc.; Maina et al. 2011). DHMs: degree heating months. Best-fit lines are included when either linear or polynomial relationships were statistically significant with $95 \%$ CI 
Table 5. Tests of entanglement of coral communities with and between shortand long-term sea surface temperatures (SST). G-test results of correspondence between coral community clusters and the SST clusters based on $90 \mathrm{~d}$ prior to sampling, daily long-term SSTs and monthly long-term SSTs from 1985-2015. We also present the cluster dendrogram entanglement values where 0 is low (strong correspondence) and 1 is high entanglement (low correspondence). $U$ is the negative log likelihood or uncertainty of the model parameters. $R^{2}(U)$ is also a measure of performance of prediction

\begin{tabular}{|lccccc|}
\hline Correspondence & $\begin{array}{c}\text { Entangle- } \\
\text { ment }\end{array}$ & df & $G$ & $\mathrm{p}$ & $\mathrm{R}^{2}$ (U) \\
\hline (A) Short term SST cluster & & & & & \\
$\begin{array}{l}\text { Long-term daily SST clusters } \\
\text { Long-term monthly clusters }\end{array}$ & 0.47 & 50 & 268.9 & 0.0001 & 0.37 \\
(B) Long-term SST monthly clusters & 0.55 & 60 & 339.9 & 0.0001 & 0.47 \\
Long-term daily SST clusters & 0.80 & 120 & 735.9 & 0.0001 & 0.77 \\
(C) Coral community clusters & & & & & \\
Short term clusters (90 d) & 0.61 & 25 & 93.4 & 0.0001 & 0.12 \\
Long-term daily SST clusters & 0.75 & 60 & 285.7 & 0.0001 & 0.38 \\
Long-term monthly SST clusters & 0.42 & 72 & 349.1 & 0.0001 & 0.46 \\
\hline
\end{tabular}

served no long-term changes in taxa at each site, correlations between 2016 and past warm years indicate a declining strength of responses and predictability at the taxa level (Fig. 7). Where site-repeated bleaching observations over time are available, there is evidence for declining bleaching intensity when corals are exposed to similar thermal stresses (McClanahan 2017, Hughes et al. 2019). Each of these taxa may be responding to different quantitative and qualitative aspects of stress over time, which would lead to poor between-year correlations. Similarly, changes in the coral genotypes and phenotypes over time through differential mortality and acclimation would also produce weak between-

ature patterns shows that these thermal stress patterns are partially repeated but not strictly geographically consistent (Selig et al. 2010). While we ob- warm year correlations in responses. The net effect is a declining ability to predict the future based on past responses. Our categorization based on temperature

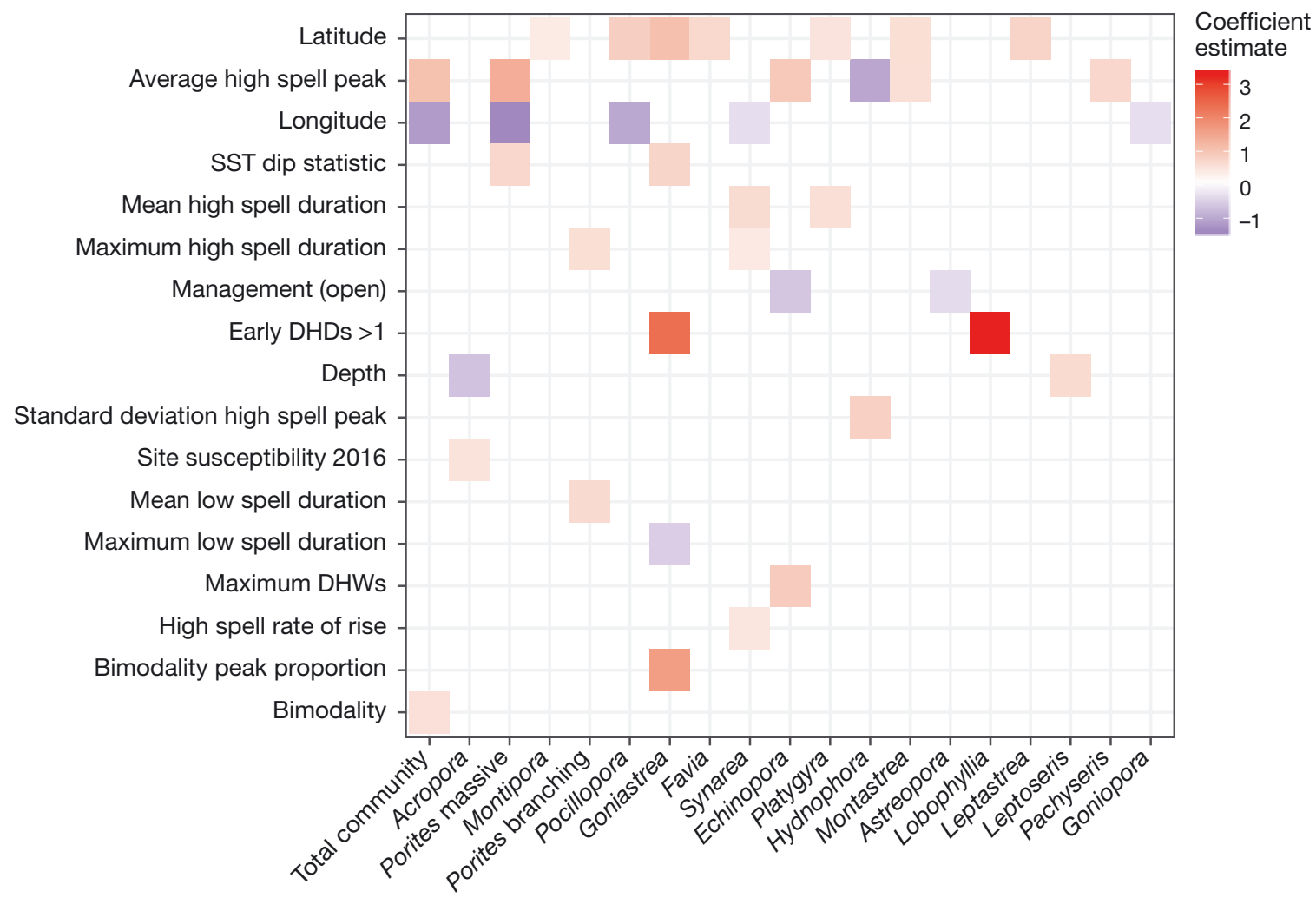

Fig. 6. Model coefficients for single environmental predictors of bleaching for 18 of the most common coral taxa (blue: significant negative model relationship; red: significant positive model relationship). Coral genera are ordered left to right on the $x$ axis from most to least abundant. In total, significant relationships with environmental predictors were found for 20 taxa (out of 30); 2 taxa did not respond significantly to single variables and their results are in the additive and interactive significant relationships presented in Fig. 8. SST: sea surface temperature; DHDs: degree heating days; DHWs: degree heating weeks 


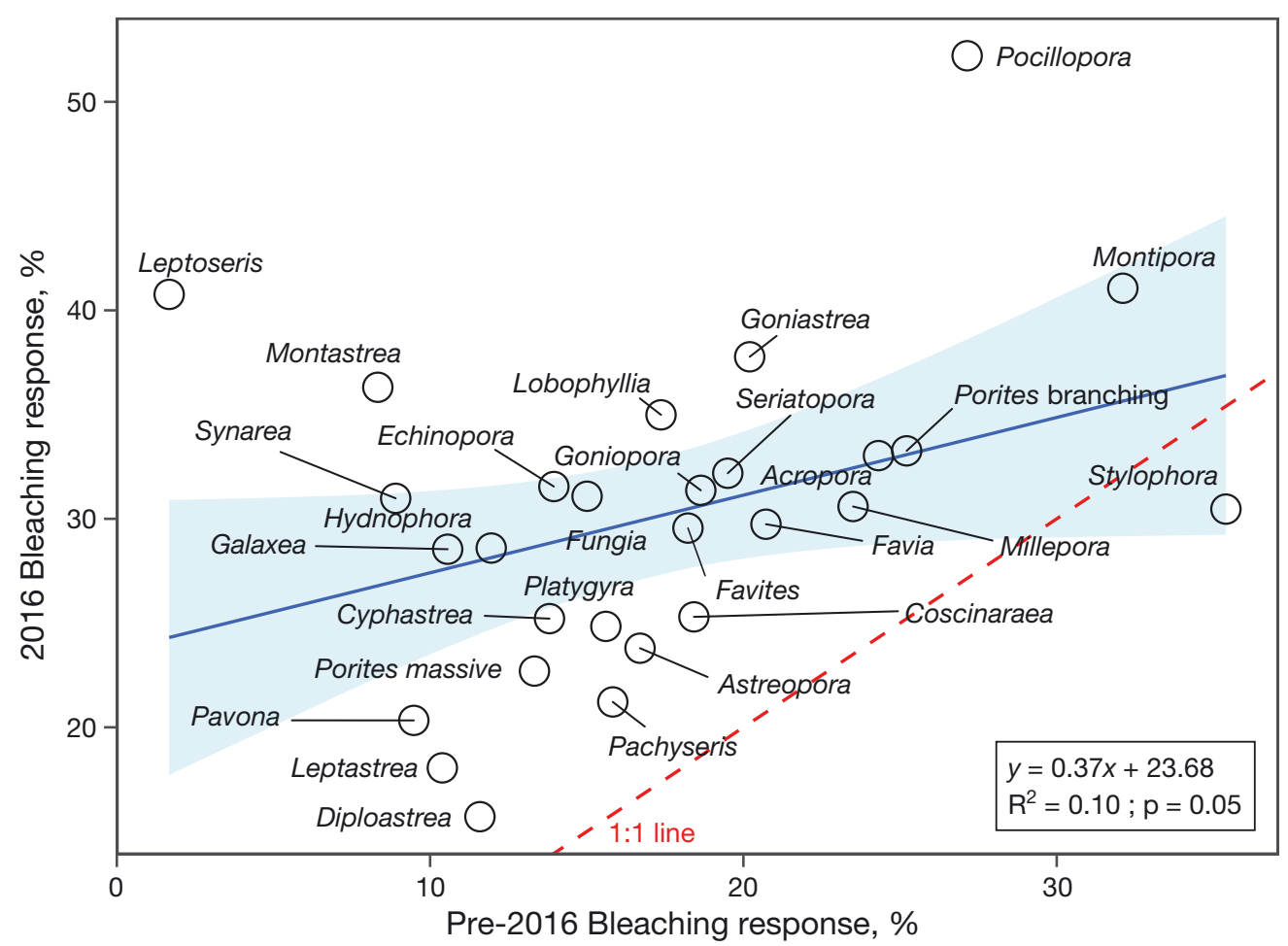

Fig. 7. By-taxon coral bleaching response comparisons of pre2016 and 2016 bleaching events, based on bleaching responses in 5 countries of the western Indian Ocean. Pre-2016 bleaching based on observations collected between 1998 and 2013 during warm years (bleaching intensity $>10 \%$ ). Blue line and shading: best fits to the data with $95 \%$ confidence intervals; red dashed line: expected 1:1 relationship assuming no change over time stress patterns alone does not, however, account for other non-measured factors. These would include a number of local unstudied factors, such as cyclones, crown-of-thorns starfish, habitat, sediments, and water quality that affect coral health, distributions, and community composition, which could explain some of the variation reported here (Hughes et al. 2003).

Taxon and genotypic replacement has likely occurred in the equatorial sites that we studied, where lower than expected abundance of thermally sensitive taxa has been recorded (Darling et al. 2019). Many of these equatorial corals are likely to have experienced repeated thermal stress disturbances (Fig. 2B). We suggest that replacement is, however, not just a simple matter of latitudinal geography but is likely to occur where thermal disturbances are frequent, background variation in SSTs is low, and where corals have lower sensitivity to thermal stresses (McClanahan et al. 2007, Safaie et al. 2018). Here, we see these thermal environments were dominated by historically thermally tolerant massive Porites and associated taxa in 2016. In 2016, Porites and the associated community bleached more than would be historically predicted, suggesting that bleaching may have increasingly become a response to thermal stress. In contrast, environments with cooler water, higher background temperature variation, but less extreme or rare warm temperatures were frequently occupied by the Acropora-dominated com- munity. Bleaching in 2016 was less than predicted based on historical observations (McClanahan et al. 2004). These observations indicate acclimation/ adaptation apart from bleaching in these environments. Consequently, many of the generalizations emerging from early observation may increasingly lose their predictive ability as corals respond to disturbances and reorganize with ongoing climate change. The findings presented here suggest that generalization about bleaching based on life histories and previous or early exposure observations may be difficult to make as inducers and responses change with time.

We suggest that as climate change accelerates and thermal stresses expand geographically, the types of stressors and responses will vary with the acclimation and adaptive potential of each coral taxon. Empirical and theoretical work from other ecosystems suggests that novel post-disturbance responses should emerge to weaken simple predictions of early and rapid environmental change (Wolkovich et al. 2014). A specific problem for accurate reef predictions is that the common DHWs metric will decline in predictive strength as coral communities respond to novel and complex thermal environments (Donner \& Carilli 2019). Consequently, additional metrics and multi-stressor models supported by repeated largescale monitoring and testing will be needed to test and improve predictions. However, given the diverse, taxon- and context-specific responses found here, 


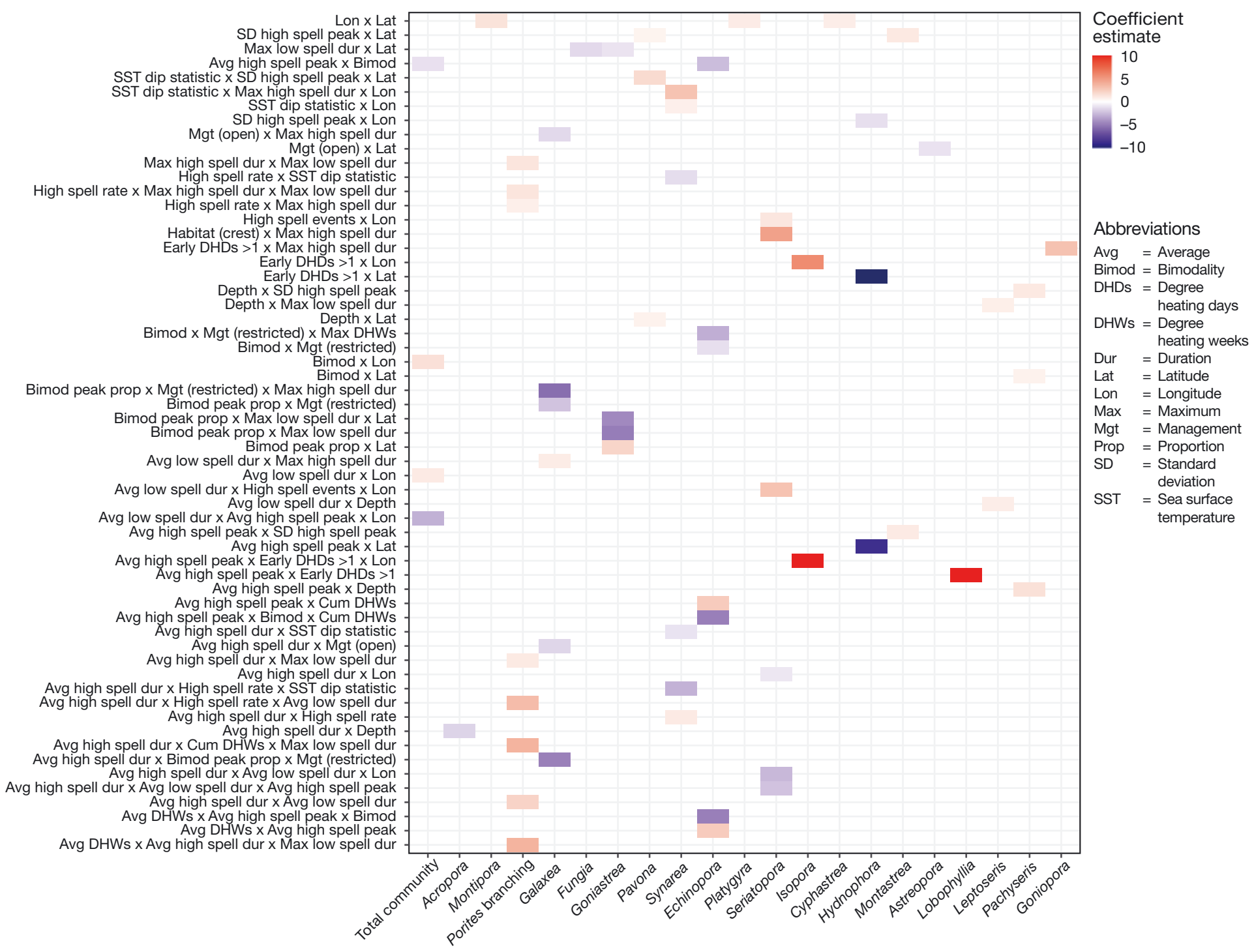

Fig. 8. Coral taxon significant responses to acute multiple interacting environmental exposure factors, showing the direction and effect sizes of significant multiple interacting environmental factors on coral taxa. Coral genera ordered from most to least abundant on the $x$-axis

complex multivariate or possibly taxon- and locationspecific models will be needed.

At the taxon level, there were a variety of responses that challenge efforts to evaluate reef-level responses, especially as dominance by sensitive taxa declines (Darling et al. 2019). Communities and taxa exhibit some change, as some bleach and acclimatize while those that die are no longer part of the adaptive system (Buddemeier et al. 2004, van Woesik et al. 2012, Donner \& Carilli 2019). Nevertheless, at the reef and functional level, losses of Acropora cover will reduce calcification, reef growth, and diminish the capacity for reefs to cope with rising sea levels (Perry et al. 2018). Clearly, thermal sensitivity will change over time, and understanding it better will improve predictions for reef states and human impacts (Wolkovich et al. 2014). By using a standard methodology to describe site-level bleaching metrics and taxon-specific responses, we highlight that satellites and collaborative field monitoring and evaluations can comprehensively document the emerging patterns provoked by climate change. These types of analyses are critical for resilience-based management where policies and management actions support natural processes that promote resistance and recovery (Mcleod et al. 2019). Our findings here imply that many current models are based on historical observations that may be less predictive as climate change dynamics unfold. 
Acknowledgements. T.R.M. and N.A.M. received support from the John D. and Catherine T. MacArthur Foundation, and the Sustainable Poverty Alleviation from Coastal Ecosystem Services (SPACES) project, number NE-K010484-1. E.S.D. was supported by an NSERC Banting Postdoctoral Fellowship and the John D. and Catherine T. MacArthur Foundation. Data collection in the Solomon Islands was supported by the Wallace Research Foundation, and the Waitt Foundation supported data collection in Fiji. Maldives data collection was supported by IUCN and USAID. M.M.M.G. received support from the French National Research Agency under the STORISK project (no. ANR-15-CE030003). Data collection in Zanzibar was partly supported by the NORHED project coordinated by the State University of Zanzibar (SUZA). The Tiffany \& Co. Foundation and the John D. and Catherine T. MacArthur Foundation supported data collection at sites in the western Indian Ocean. V.J.P. received support from the DST-INSPIRE Faculty Programme, and Z. Tyabji and S. Chandrasekhar assisted V.J.P. with data collection in the Andaman Islands. R.A. received funding support from the Pew Marine Fellowship and an Intramural Project from the Spanish National Research Council (CSIC-201330E062). S.A.K. was funded by the VILLUM Foundation (grant no. 10114). A.T.H. received funding from the Carnegie Corporation of New York. Indonesia data collection was supported by John D. and Catherine T. MacArthur Foundation and Margaret A. Cargill Philanthropies. The following people assisted with data collection: A. Baird, A. Halford, S. Keith, C. Miternique, E. Montocchio, C. Muhando, J. Ndagala, and N. Summers.

\section{LITERATURE CITED}

Ainsworth TD, Heron SF, Ortiz JC, Mumby PJ and others (2016) Climate change disables coral bleaching protection on the Great Barrier Reef. Science 352:338-342

Barton AD, Casey KS (2005) Climatological context for large-scale coral bleaching. Coral Reefs 24:536-554

Bjørnstad ON (2013) Package ncf: spatial nonparametric covariance functions. R package version 1.1-5. http://onb. ent.psu.edu/onb1/R

Brandmaier AM (2015) pdc: an R package for complexitybased clustering of time series. J Stat Softw 67:1-23

Brooks ME, Kristensen K, van Benthem KJ, Magnusson A and others (2017) glmmTMB balances speed and flexibility among packages for zero-inflated generalized linear mixed modeling. R J 9:378-400

Buddemeier RW, Baker AC, Fautin DG, Jacobs JR (2004) The adaptive hypothesis of bleaching. In: Rosenberg E, Loya Y (eds) Coral health and disease. Springer, Berlin Heidelberg, p 427-444

Warling ES, McClanahan TR, Côté IM (2013) Life histories predict coral community disassembly under multiple stressors. Glob Change Biol 19:1930-1940

* Darling ES, McClanahan TR, Maina J, Gurney GG and others (2019) Social-environmental drivers inform strategic management of coral reefs in the Anthropocene. Nat Ecol Evol 3:1341-1350

Donner SD, Carilli J (2019) Resilience of Central Pacific reefs subject to frequent heat stress and human disturbance. Sci Rep 9:3484

Donner SD, Skirving WJ, Little CM, Oppenheimer M, Hoegh-Gulberg O (2005) Global assessment of coral bleaching and required rates of adaptation under climate change. Glob Change Biol 11:2251-2265
Eakin CM, Morgan JA, Heron SF, Smith TB and others (2010) Caribbean corals in crisis: record thermal stress, bleaching, and mortality in 2005. PLOS ONE 5:e13969

* Edmunds PJ, Adjeroud M, Baskett ML, Baums IB and others (2014) Persistence and change in community composition of reef corals through present, past, and future climates. PLOS ONE 9:e107525

Ellison AM (1987) Effect of seed dimorphism on the densitydependent dynamics of experimental populations of Atriplex triangularis (Chenopodiaceae). Am J Bot 74: 1280-1288

Freeman JB, Dale R (2013) Assessing bimodality to detect the presence of a dual cognitive process. Behav Res Methods 45:83-97

*Frieler K, Meinshausen M, Golly A, Mengel M, Lebek K, Donner SD, Hoegh-Guldberg O (2013) Limiting global warming to $2^{\circ} \mathrm{C}$ is unlikely to save most coral reefs. Nat Clim Chang 3:165-170

*Gelman A (2008) Scaling regression inputs by dividing by two standard deviations. Stat Med 27:2865-2873

*Gaham MH (2003) Confronting multicollinearity in ecological multiple regression. Ecology 84:2809-2815

*Gaham NA, Jennings S, MacNeil MA, Mouillot D, Wilson SK (2015) Predicting climate-driven regime shifts versus rebound potential in coral reefs. Nature 518:94-97

Grottoli AG, Warner ME, Levas SJ, Aschaffenburg MD and others (2014) The cumulative impact of annual coral bleaching can turn some coral species winners into losers. Glob Change Biol 20:3823-3833

Harrell FE Jr (2001) Resampling, validating, describing, and simplifying the model. Springer, New York, NY, p 87-103

* Hartigan JA, Hartigan PM (1985) The dip test of unimodality. Ann Stat 13:70-84

Hoegh-Guldberg O (1999) Climate change, coral bleaching and the future of the world's coral reefs. Mar Freshw Res 50:839-866

*Hughes TP, Baird AH, Bellwood DR, Card M and others (2003) Climate change, human impacts, and the resilience of coral reefs. Science 301:929-933

* Hughes TP, Kerry JT, Álvarez-Noriega M, Álvarez-Romero JG and others (2017) Global warming and recurrent mass bleaching of corals. Nature 543:373-377

*Hughes TP, Kerry JT, Baird AH, Connolly SR and others (2018a) Global warming transforms coral reef assemblages. Nature 556:492-496

* Hughes TP, Anderson KD, Connolly SR, Heron SF and others (2018b) Spatial and temporal patterns of mass bleaching of corals in the Anthropocene. Science 359: 80-83

* Hughes TP, Kerry JT, Connolly SR, Baird AH and others (2019) Ecological memory modifies the cumulative impact of recurrent climate extremes. Nat Clim Chang 9: $40-43$

Kleypas JA, Danabasoglu G, Lough JM (2008) Potential role of the ocean thermostat in determining regional differences in coral reef bleaching events. Geophys Res Lett 35:L03613

*Legendre P, Fortin MJ (1989) Spatial pattern and ecological analysis. Vegetatio 80:107-138

* Liu G, Heron SF, Eakin CM, Muller-Karger FE and others (2014) Reef-scale thermal stress monitoring of coral ecosystems: new 5-km global products from NOAA coral reef watch. Remote Sens 6:11579-11606

* Maina J, Venus V, McClanahan TR, Ateweberhan M (2008) Modelling susceptibility of coral reefs to environmental 
stress using remote sensing data and GIS models in the western Indian Ocean. Ecol Modell 212:180-199

Maina J, McClanahan TR, Venus V, Ateweberhan M, Madin J (2011) Global gradients of coral exposure to environmental stresses and implications for local management. PLOS ONE 6:e23064

Mantel N (1967) Ranking procedures for arbitrarily restricted observation. Biometrics 23:65-78

Maynard JA, Turner PJ, Anthony KR, Baird AH and others (2008) ReefTemp: an interactive monitoring system for coral bleaching using high-resolution SST and improved stress predictors. Geophys Res Lett 35:L05603

McClanahan TR (2017) Changes in coral sensitivity to thermal anomalies. Mar Ecol Prog Ser 570:71-85

McClanahan TR, Maina J (2003) Response of coral assemblages to the interaction between natural temperature variation and rare warm-water events. Ecosystems 6: 551-563

McClanahan TR, Muthiga NA, Mangi S (2001) Coral and algal changes after the 1998 coral bleaching: interaction with reef management and herbivores on Kenyan reefs. Coral Reefs 19:380-391

McClanahan TR, Baird AH, Marshall PA, Toscano MA (2004) Comparing bleaching and mortality responses of hard corals between southern Kenya and the Great Barrier Reef, Australia. Mar Pollut Bull 48:327-335

* McClanahan TR, Ateweberhan M, Graham NAJ, Wilson SK, Sebastián CR, Guillaume MM, Bruggemann JH (2007) Western Indian Ocean coral communities: bleaching responses and susceptibility to extinction. Mar Ecol Prog Ser 337:1-13

McClanahan TR, Ateweberhan M, Darling ES, Graham NAJ, Muthiga NA (2014) Biogeography and change among regional coral communities across the Western Indian Ocean. PLOS ONE 9:e93385

McClanahan TR, Weil E, Baird AH (2018) Consequences of coral bleaching for sessile reef organisms. In: van Oppen $\mathrm{MJH}$, Lough JM (eds) Coral bleaching: patterns, processes, causes and consequences, $2^{\text {nd }}$ edn. Ecological Studies No. 233. Springer International Publishing, Cham, p 231-261

McClanahan TR, Darling ES, Maina JM, Muthiga NA and others (2019) Temperature patterns and mechanisms influencing coral bleaching during the 2016 El Niño. Nat Clim Change 9:845-851

Mcleod E, Anthony KRN, Mumby PJ, Maynard J and others (2019) The future of resilience-based management in coral reef ecosystems. J Environ Manage 233:291-301

Palumbi SR, Barshis DJ, Traylor-Knowles N, Bay RA (2014)

Editorial responsibility: Peter Edmunds,

Northridge, California, USA
Mechanisms of reef coral resistance to future climate change. Science 344:895-898

Pandolfi JM, Connolly SR, Marshall DJ, Cohen AL (2011) Projecting coral reef futures under global warming and ocean acidification. Science 333:418-422

Perry CT, Alvarez-Filip L, Graham NA, Mumby PJ and others (2018) Loss of coral reef growth capacity to track future increases in sea level. Nature 558:396-400

R Core Team (2017) R: a language and environment for statistical computing. R Foundation for Statistical Computing, Vienna

* Safaie A, Silbiger NJ, McClanahan TR, Pawlak G and others (2018) High frequency temperature variability reduces the risk of coral bleaching. Nat Commun 9:1671

Selig ER, Casey KS, Bruno JF (2010) New insights into global patterns of ocean temperature anomalies: implications for coral reef health and management. Glob Ecol Biogeogr 19:397-411

Skirving WJ, Heron SF, Marsh BL, Liu G, De La Cour JL, Geiger EF, Eakin CM (2019) The relentless march of mass coral bleaching: a global perspective of changing heat stress. Coral Reefs 38:547-557

Strong AE, Liu G, Meyer J, Hendee JC, Sasko D (2004) Coral reef watch 2002. Bull Mar Sci 75:259-268

* Sully S, Burkepile DE, Donovan MK, Hodgson G, van Woesik R (2019) A global analysis of coral bleaching over the past two decades. Nat Commun 10:1264

* Thompson DM, van Woesik R (2009) Corals escape bleaching in regions that recently and historically experienced frequent thermal stress. Proc R Soc B 276:2893-2901

*van Woesik R, Franklin EC, O'Leary JK, McClanahan TR, Klaus JS, Budd AF (2012) Hosts of the Plio-Pleistocene past reflect modern-day coral vulnerability. Proc R Soc B 279:2448-2456

Veron JEN (2000) Corals of the world, Vol 1-3. Australian Institute of Marine Science, Townsville

West JM, Salm RV (2003) Resistance and resilience to coral bleaching: implications for coral reef conservation and management. Conserv Biol 17:956-967

*Wolkovich EM, Cook BI, McLauchlan KK, Davies TJ (2014) Temporal ecology in the Anthropocene. Ecol Lett 17: 1365-1379

Zimprich D (2010) Modeling change in skewed variables using mixed beta regression models. Res Hum Dev 7: 9-26

Zuur A, Leno EN, Walker N, Saveliev AA, Smith GM (2009) Mixed effects models and extensions in ecology with R. Springer, New York, NY

Submitted: March 23, 2020; Accepted: June 25, 2020

Proofs received from author(s): August 17, 2020 